KeMAS 10 (2) (2015)
Jttp://journal.unnes.ac.id/nju/index.php/kemas

\title{
KINERJA PETUGAS DALAM PENCATATAN DAN PELAPORAN PWS KIA DI PUSKESMAS DUREN
}

Yudhy Dharmawan ${ }^{\bowtie}$, Putri Asmita Wigati, Fifi Dwijayanti

Fakultas Kesehatan Masyarakat, Universitas Diponegoro Semarang

\section{Info Artikel}

Sejarah Artikel:

Diterima 22 Oktober 2014

Disetujui 25 November 2014

Dipublikasikan Januari 2015

Keywords:

Data Quality;

Local Area Monitoring of

$\mathrm{MCH}$

\begin{abstract}
Abstrak
Angka kematian Ibu dan Bayi di Jateng masih tinggi. Kejadian kematian tersebut juga terdapat diwilayah kerja Puskesmas Duren. PWS KIA adalah alat manajemen yang sudah dikembangkan oleh Kemenkes RI, untuk mendeteksi dini penyebab kematian bayi dan ibu. Dengan deteksi sedini mungkin, maka penyebab kematian dapat dihindarkan dan berakibat pada menurunnya angka kematian ibu dan bayi. Namun demikian kenyataan dilapangan menunjukkan bahwa masih terdapat ketidak lengkapan, ketidak akuratan dan keterlambatan pelaporan PWS KIA, termasuk di Puskesmas Duren, Kec. Bandungan, Kab. Semarang. Oleh karena itu perlu diketahui faktor apa saja yang terkait dengan kinerja petugas puskesmas dalam kegiatan PWS KIA. Penelitian bersifat observasional deskriptif, dengan pendekatan crosssectional,dengan analisis data kuantitatif. Populasi penelitian adalah Bidan diwilayah Puskesmas Duren. Hasil menunjukkan bahwa pencatatan PWS KIA hanya menggunakan pencatatan kohort dan buku KIA, sementara Buku bantu dan Kartu ibu hampir tidak digunakan. Tingkat akurasi data pencatatan dan pelaporan hanya mencapai $70 \%$, sedangkan ketepatan waktu pelaporan hanya $80 \%$. Ada 2 bidan desa yang tidak melaporkan tepat waktu selama 2 bulan. Skor kualitas data hanya mencapai $66 \%$. Tabulasi silang menunjukan ada keterkaitan motivasi,beban kerja, fasilitas dan masa kerja terhadap kualitas data yang baik.Disarankan untuk pemberian motivasi dan menggunakan teknologi Informasi.
\end{abstract}

\begin{abstract}
Maternal and Infant mortality rate is still high in Central Java. The incidence of these deaths also occurred in the region Puskesmas Duren. Local Area Monitoring of $\mathrm{MCH}$ program is a management tool that has been developed by the Ministry of Health of Indonesia, which serves to detect the cause of the premature infant and maternal mortality. With early detection, the cause of death can be avoided and result in reduced maternal and infant mortality. However, the fact that there are in the field shows that there is still a lack of completeness, inaccuracies and delays in reporting of Local Area Monitoring of MCH, including Puskesmas Duren, District Bandungan, Semarang regency Therefore, it is important to know what factors are associated with health center personnel in the performance of the Local Area Monitoring of MCH activities. The Research is a descriptive observational study, the cross-sectional approach, the quantitative data analysis. Population of this study was the midwife who worked in the region Puskesmas Duren. Result of this study were used Recording Document are Kohort and Buku KIA. The level of accuracy of data recording and reporting only reached $70 \%$, while the timeliness of reporting only $80 \%$. There are two midwives who do not report on time for 2 months. Data quality scores only reached $66 \%$. Cross-tabulation showed there is linkage motivation, workload, facilities and working period with the quality of data. Suggestion for motivation and use of information technology
\end{abstract}

(C) 2015 Universitas Negeri Semarang 


\section{Pendahuluan}

Angka Kematian Ibu di Jawa Tengah pada tahun 2012 telah mencapai 116,34 per 100.000 kelahiran hidup dengan penyebab kematian antara lain perdarahan, infeksi, eklamsi, dan lain-lain (Target Nasional 102 per 100.000 kelahiran hidup). Sedangkan angka kematian bayi/neonatus pada tahun yang sama di Jawa Tengah sebesar 10,37 per 1000 kelahiran hidup dengan penyebab kematiannya antara lain BBLR, Asfiksia, Pneumonia, Diare, ISPA, Prematur, Kongenital, dll. (Dinkes Prop. Jateng, 2013).

Menurut hasil Riskesdas 2007 penyebab langsung kematian ibu, bayi dan balita sebetulnya merupakan penyebab dapat dicegah jika dapat terdeteksi secara dini. Oleh karena itu dikembangkan alat manajemen untuk menedeteksi dini pennyebab kematian tersebut berupa pemantauan wilayah setempat kesehatan ibu dan anak (PWS KIA) agar dapat dilakukan tindak lanjut yang cepat dan tepat terhadap permasalahan KIA yang dihadapi. Dengan PWS KIA diharapkan cakupan pelayanan dapat ditingkatkan dengan menjangkau seluruh sasaran di suatu wilayah kerja, sehingga seluruh kasus dengan faktor risiko atau komplikasi dapat ditemukan sedini mungkin agar dapat memperoleh penanganan yang memadai. (Depkes RI, 2009).

Kurangnya sumber daya manusia yang kompeten dalam pengelolaan data juga menjadi faktor yang mengakibatkan lemahnya sistem pencatatan dan pelaporan terutama dalam hal manajemen data, termasuk dalam sistem PWS KIA. Jumlah SDM yang tersedia di lapangan masih kurang bila dibandingkan dengan jumlah inisiatif penguatan sistem informasi kesehatan secara manual ataupun terkomputerisasi (Kemenkes RI, 2012).

Hal tersebut sesuai dengan penelitian yang dilakukan oleh Hari Basuki Notobroto di Jawa Timur, yang menemukan masih adanya petugas yang pengetahuan dan sikapnya kurang, terutama dari sisi kelengkapan data dan pencapaian target dimana masih dijumpai petugas yang mengganti datanya. Akurasi Data Puskesmas juga masih kurang. (Hari, 2005 ) Hal yang sama juga ditemui oleh Ingan Tarigan, ditemukan kualitas pelaporan belum baik, dikarenakan belum tepat waktu pelaporan dan tidak melakukan secara rutin. Dari sisi pemanfaatan data juga baru mencapai 33\% standar kualitas (Ingan, 2009).

Bila pencatatan dilakukan secara lengkap dan penyerahannya dilakukan tepat waktu maka gambaran status kesehatan ibu dan anak dapat dinilai sehingga setiap terjadi masalah dapat dideteksi sedini mungkin dan mendapatkan penanganan yang baik. Namun seringkali ditemukan dalam system pencatatan dan pelaporan PWS KIA masih ditemukan banyak kendala. Hasil penelitian Arwida membuktikan bahwa informasi (Output) dalam PWS KIA sering tidak akurat dan tidak tepat waktu karena masih dikerjakan secara manual. Hal ini dikarenakan ada masalah dari saat penangkapan data (Input), dimana penulisan data tidak tepat dan lengkap. Masalah juga ditemukan pada saat perekapan dan pembuatan salinan untuk pembuatan laporan (proses), seperti pada perekapan data di buku bantu pada Bidan Desa, maupun perekapan dan penyalinan buku bantu ke dalam format pelaporan di tingkat puskesmas.

Pelaksanaan PWS KIA sangat tergantung pada sumber daya manusia yang handal, terutama tenaga bidan yang sangat berperan besar sebagai ujung tombak kegiatan tersebut di lapangan, padahal pemahaman Bidan Desa tentang materi PWS KIA belum secara baik dan benar diaplikasikan lapangan.

Puskesmas Duren adalah puskesmas yang terdapat diwilayah Kecamatan Bandungan, Kabupaten Semarang. Kematian bayi masih terdapat di wilayah Puskesmas Duren. Sebagaimana program Nasional, maka PWS KIA juga sudah dilakukan secara manual di Puskesmas Durenan. Namun masih ditemukan banyak masalah terkait pencatatan dan pelaporan PWS KIA. Masalah penangkapan data, masih belum samanya persepsi Bidan Desa terhadap batasan data yang harus dicatat, pelaporan ke Puskesmas juga sering tidak lengkap dan termasuk terlambat. Hal tersebut, pada akhirnya akan mempengaruhi kualitas informasi yang akan dihasilkan baik pada tingkat puskesmas, kabupaten/Kota, Propinsi, hingga tengkat Nasional.

Permasalahan tersebut berdampak pada proses pengolahan serta informasi yang dihasilkan. Keterlambatan pelaporan data yang 
dikirimkan dapat mengganggu kelancaran dalam pengumpulan, penghitungan, dan pengolahan data sehingga dalam penyajian informasi pun mengalami keterlambatan. Keterlambatan dan ketidaksesuaian pengolahan data dapat disebabkan karena faktor beban kerja dan motivasi. Pengolahan data yang dilakukan secara manual dapat mempengaruhi keakuratan data yang dilaporkan. Ketidaksesuaian antar data dapat disebabkan karena kurangnya motivasi petugas dan kurangnya supervisi yang dilakukan oleh Bidan Koordinator Puksesmas maupun Dinas Kesehatan Kabupaten, serta perbedaan persepsi antar bidan desa.

Oleh karena itu dengan berdasar pada permasalahan-permasalahan diatas perlu diketahui beberapa faktor yang berhubungan dengan kinerja bidan dalam pencatatan dan pelaporan PWS KIA. Penelitian dilakukan dengan menilai kinerja bidan desa dilihat dari data PWS KIA yang dilaporkan .

\section{Metode}

Penelitian ini dilakukan selama enam bulan dimulai bulan April sampai dengan September 2014. Objek pencatatan dan pelaporan yang diamati adalah pada bulan Juni dan Juli 2014. Jenis penelitian yang digunakan adalah penelitian Observasional dengan metode survey dengan tujuan untuk mendeskripsikan keterkaitan antar variabel yang diteliti dengan analisis kuantitatif dan pendekatan cross sectional (sewaktu).

Variabel independen dalam penelitian ini terdiri dari masa kerja, persepsi, motivasi, beban kerja, supervisi dan fasilitas. Sedangkan variabel dependen dalam penelitian ini terdiri dari kinerja pencatatan dan pelaporan PWS KIA yang dilihat dari segi kelengkapan dokumen, keakuratan data dan ketepatan waktu pelaporan.

Populasi penelitian adalah seluruh Bidan Desa yang ada diwilayah kerja Puskesmas Duren. Instrumen pengumpulan data menggunakan kuesioner, dengan menggunakan metode wawancara, untuk menghindari bias.

Analisis data dengan menggunakan metode Analisis Statistik deskriptif untuk mendeskripsikan masing masing variabel dan tabulasi silang untuk mengetahui keterkaitan antara variabel dependen dan variabel independen. Laporan PWS KIA yang diukur terdiri dari 7 form yaitu form ibu hamil (Form 1), form data persalinan dan nifas (Form 2), form data neonatal (Form 3), form data kematian ibu (Form 4), form data kematian bayi balita (Form 5), form data program PWS K1 dan K4 (Form 6) dan form data program PWS persalinan nakes dan KN (Form 7).

\section{Hasil dan Pembahasan}

Berdasarkan hasil penghitungan lembar observasi mengenai kelengkapan, diketahui bahwa Berdasarkan tabel diketahui bahwa hampir semua bidan desa di Kecamatan Bandungan memiliki dokumen yang tidak lengkap (50\%) terutama pada dokumen buku bantu dan kartu ibu. Berdasarkan sumber datanya, dapat diketahui bahwa sumber data yang paling rendah kelengkapannya yaitu buku bantu (2.86\%) dan buku kartu ibu (0\%), sedangkan yang paling lengkap yaitu kohort dan buku KIA $(100.00 \%)$.

Kelengkapan dokumen bidan desa di Kecamatan Bandungan masih tergolong rendah, karena masih banyak bidan desa yang tidak memiliki beberapa dokumen dalam melakukan pencatatan dan pelaporan yang seharusnya dimiliki oleh bidan desa sesuai pedoman PWS.

Kelengkapan dokumen sangat diperlu-

Tabel 1. Rekapitulasi kelengkapan form di setiap sumber datanya

\begin{tabular}{cccccccccc}
\hline No & Desa & Form 1 & Form 2 & Form 3 & Form 4 & Form 5 & Form 6 & Form 7 & $\begin{array}{c}\text { Keleng } \\
\text { kapan (\%) }\end{array}$ \\
\hline 1 & Buku Bantu & 0.00 & 20.00 & 0.00 & 0.00 & 0.00 & 0.00 & 0.00 & 2.86 \\
2 & Kohort & 100 & 100 & 100 & 100 & 100 & 100 & 100 & 100.00 \\
3 & Kartu Ibu & 0 & 0 & 0 & 0 & 0 & 0 & 0 & 0.00 \\
4 & Buku KIA & 100.00 & 100.00 & 100.00 & 100.00 & 100.00 & 100.00 & 100.00 & 100.00 \\
\hline & Kelengkapan (\%) & 50.00 & 55.00 & 50.00 & 50.00 & 50.00 & 50.00 & 50.00 & \\
\hline
\end{tabular}

Sumber : data primer 
Tabel 2. Rekapitulasi keakuratan data PWS KIA

\begin{tabular}{|c|c|c|c|c|c|c|c|c|c|}
\hline No & Bulan & Form 1 & Form 2 & Form 3 & Form 4 & Form 5 & Form 6 & Form 7 & $\begin{array}{c}\text { Keaku } \\
\text { ratan } \\
(\%)\end{array}$ \\
\hline 1 & Juni & 40.00 & 40.00 & 40.00 & 100.00 & 100.00 & 100.00 & 80.00 & 71,42 \\
\hline 2 & Juli & 60.00 & 20.00 & 40.00 & 100.00 & 100.00 & 80.00 & 80.00 & 68,58 \\
\hline \multicolumn{2}{|r|}{ Rata Rata (\%) } & 50.00 & 30.00 & 40.00 & 100.00 & 100.00 & 90.00 & 80.00 & 70 \\
\hline
\end{tabular}

Sumber : data primer

Keterangan :

Form 1 : Form Ibu Hamil

Form 2 : Form Persalinan dan Nifas

Form 3 : Form Neonatal

Form 4 : Form Data kematian ibu

Form 5 : Form Data kematian bayi balita

Form 6 : Form Data Program PWS K1 dan K4

Form 7 : Form Data Program PWS Persalinan Nakes dan KN

kan untuk menyusun perencanaan, evaluasi dan pengambilan keputusan, untuk manajemen KIA. Pencatatan di Kohort dilakukan oleh Bidan, karena pada supervisi hanya pencatatan di kohort itulah yang selalu ditanyakan, meskipun di buku pedoman PWS KIA seharusnya ada dokumen pencatatan lain yang harus dilakukan. Menurut keterangan Bidan, meskipun pencatatan lain lengkap, tapi pencatatan kohort tidak lengkap maka tetap dianggap dokumennya tidak lengkap.

Penghitungan keakuratan data dengan melakukan penghitungan ulang hasil pencatatan data yang dilakukan oleh bidan desa, dibandingkan dengan data pelaporan yang dilaporkan bidan desa ke Bidan koordinator. Penghitungan dilakukan pada tiap form pelaporan PWS, pada 5 bidan Desa selaku populasi yang ada di Puskesmas Duren. Prosentase kekauratan didapatkan dari tiap form yang pengghitungannya akurat pada ke 5 bidan desa tersebut.

Keakuratan data pada form laporan KIA pada bulan Juni sebagian besar tidak akurat, hanya pada form 4 (form data kematian ibu), form 5 (form data kematian bayi balita) dan form 6 (form data program PWS K1 dan K4) dengan persentase sebesar $100 \%$. Keakuratan data yang paling rendah yaitu form 1,2 dan 3 dengan persentase sebesar $40 \%$. Sedangkan keakuratan data laporan PWS KIA pada bulan Juli pada form 2 (form data persalinan dan nifas) yang memiliki keakuratan paling rendah dengan persentase $20 \%$. Secara keseluruhan hanya form 4 (form data kematian ibu), dan form 5 (form data kematian bayi balita) yang memilki keakuratan $100 \%$ pada kedua bulan tersebut. Selengkapnya keakuratan pelaporan dapat dilihat pada tabel 2 berikut ini

Berdasarkan penghitungan diatas Keakuratan hanya diperhatikan pada laporan kematian saja, dikarenakan laporan inilah yang sering menjadi perhatian program KIA, terutama untuk pencapaian target program MDG's. Bila dilihat berdasarkan bulannya, tingkat keakuratan data bidan desa semakin lama mengalami penurunan. Hal ini terlihat dalam penelitian yang dilakukan selama dua bulan terakhir yaitu Juni dan Juli.

Hasil diatas juga menunjukkan bahwa keakuratan data juga hanya diperlukan pada laporan yang menjadi prioritas saja, yaitu laporan kematian. Padahal data yang akurat diperlukan untuk perencanaan maupun manajemen pengambilan keputusan, sehingga semua laporan seharusnya akurat.

Berdasarkan penghitungan lembar observasi ketepatan waktu pelaporan, diketahui bahwa sebagian besar bidan desa sudah tepat waktu dalam pengumpulan laporan. Hal ini terlihat bahwa hanya 3 dari 5 bidan desa mengumpulkan laporan selalu tepat pada waktunya, yaitu desa Duren, Kenteng dan Candi. Hal ini menunjukkan bahwa masih ada bidan desa yang belum mengerti ketepatan waktu dalam mengumpulkan laporan data. Ketepatan waktu dalam pengumpulan laporan data sangat penting. Laporan data yang tepat waktu memperce- 
pat pengambilan keputusan, sehingga masalah bisa secara cepat diselesaikan. Selengkapnya ketepatan waktu pelaporan menurut Bidan Desa dapat disajikan dalam tabel 3 berikut ini :

Tabel 3. Hasil penghitungan ketepatan waktu pelaporan bidan desa

\begin{tabular}{clccc}
\hline No & \multicolumn{1}{c}{ Desa } & Juni & Juli & $\begin{array}{c}\text { Ketepatan } \\
\text { Waktu }(\%)\end{array}$ \\
\hline 1 & Duren & Tepat & Tepat & 100 \\
2 & Bandungan & Tepat & Tidak & 50 \\
3 & Kenteng & Tepat & Tepat & 100 \\
4 & Candi & Tepat & Tepat & 100 \\
5 & Banyukuning & Tidak & Tepat & 50 \\
\hline \multicolumn{2}{r}{ Ketepatan Waktu } & 100 & 100 & 80 \\
\hline
\end{tabular}

Sumber : data primer

Penilaian kualitas data merupakan hasil rata-rata dari jumlah kelengkapan, keakuratan dan ketepatan waktu dalam pengumpulan laporan PWS KIA setiap bulannya. Untuk penghitungan kualitas data maka digunakan satuan desa yang ada di Wilayah Puskesmas Duren. Berikut ini adalah rekapitulasi kualitas data bidan desa di wilayah Puskesmas Duren.

Berdasarkan tabel 4. diketahui bahwa seluruh bidan desa memiliki kualitas data kurang dari $80 \%$. Berdasarkan perhitungan, desa yang memiliki kualitas data tertinggi yaitu desa Kenteng dan Candi (73.81\%), sedangkan yang terendah yaitu desa Banyukuning (54.76\%).

Berdasarkan wawancara, bidan desa yang mendapat supervisi secara rutin sebesar $80 \%$. Dalam supervisi, supervisor menjelaskan tentang pentingnya pencatatan dan pelaporan data KIA secara lengkap, akurat dan tepat waktu dengan persentase $100 \%$. Bidan koordinator tidak memberikan umpan balik yang jelas bila ada laporan yang salah (100\%). Bidan koordinator telah memberikan pembinaan dalam pengisian formulir pelaporan PWS KIA (100\%). Bidan koordinator sering melakukan evaluasi mengenai kelengkapan, ketepatan waktu, mengecek pelaporan dan memeriksa kualitas data pelaporan PWS KIA (100\%).

Berdasarkan hasil tabulasi silang diketahui bahwa kualitas data yang baik lebih banyak berasal dari supervisi yang buruk (100\%). Sedangkan kualitas data yang tidak baik lebih banyak berasal dari supervisi yang baik (50\%). Hal ini dapat dilihat dari supervisi yang telah dilakukan secara rutin, namun kualitas data masih rendah karena rumitnya pencatatan dan kedisiplinan bidan desa yang mendukung dalam pelaporan PWS KIA. Dalam supervisi, supervisor sebaiknya menjelaskan pentingnya pencatatan dan pelaporan data KIA secara lengkap, akurat dan tepat waktu, namun demikian seringkali supervisor tidak memberikan umpan balik yang jelas bila ada laporan PWS KIA yang salah. Mungkin inilah yang membuat supervisi tidak serta merta berkontribusi terhadap kualitas data.

Hasil ini sejalan dengan penelitian yang dilakukan oleh Ratih dalam mencari faktor yang berhubungan dengan kinerja kader Posyandu, tidak berhubungan dengan kunjungan dari pihak RT, Pihak Kelurahan maupun Puskesmas (Ratih, 2013 )

Supervisi dari atasan adalah salah satu faktor dalam sistem manajemen, tujuannya adalah memberikan bantuan pada bawahan secara langsung sehingga bawahan memiliki kemampuan untuk melaksanakan pekerjaan. Supervisi yang suportif, terencana dan baik merupakan faktor penting dalam keberhasilan suatu program kesehatan, termasuk dalam hal pencatatan dan pelaporan untuk meningkatkan kualitas data bidan desa.

Tabel 4. Hasil penghitungan kualitas data PWS KIA Puskesmas Duren

\begin{tabular}{cccccc}
\hline No & Desa & Keakuratan (\%) & Kelengkapan (\%) & $\begin{array}{c}\text { Ketepatan } \\
\text { Waktu (\%) }\end{array}$ & $\begin{array}{c}\text { Kualitas Data } \\
(\%)\end{array}$ \\
\hline 1 & Duren & 64.29 & 53.57 & 100 & 72.62 \\
2 & Bandungan & 78.57 & 50 & 50 & 59.52 \\
3 & Kenteng & 71.43 & 50 & 100 & 73.81 \\
4 & Candi & 71.43 & 50 & 100 & 73.81 \\
5 & Banyukuning & 64.29 & 50 & 50 & 54.76 \\
& Rata rata & 70,00 & 50 & 80 & 66,90 \\
\hline
\end{tabular}

Sumber : data primer 
Berdasarkan data wawancara, diketahui 80\% bidan desa memiliki buku atau lembar register khusus untuk menulis data PWS KIA. Bidan desa tidak menyediakan formulir senduri pelaporan data PWS KIA (80\%). Sebagian besar bidan desa melakukan pelaporan data PWS KIA secara manual (60\%).

Berdasarkan hasil tabulasi diketahui bahwa kualitas data yang tidak baik lebih banyak berasal dari kelompok ketersediaan fasilitas yang baik (40\%). Sedangkan kualitas data yang baik lebih banyak berasal dari kelompok ketersediaan fasilitas yang baik (60\%).

Fasilitas merupakan ketersediaan sarana atau peralatan yang digunakan dalam melaksanakan pelayanan pekerjaan.Untuk mencapai standar mutu pelayanan, maka fasilitas harus sesuai baik dari segi kualitas maupun kuantitas.

Berdasarkan hasil wawancara, diketahui bahwa sebagian besar bidan desa tidak mengalami kesulitan dalam pencatatan (100\%). Seluruh bidan desa di Kecamatan Bandungan setuju bahwa pelaporan data PWS KIA harus dilakukan secara lengkap dan tepat waktu, harus dikerjakan dengan penuh kesadaran tanpa harus disuruh, bidan selalu melaksanakan pelaporan walaupun tanpa adanya pengawasan dari pimpinan serta setuju jika diberlakukan sanksi agar bidan melaporkan data PWS KIA dengan lengkap dan tepat waktu.

Berdasarkan tabulasi silang menunjukkan bahwa kualitas data yang tidak baik lebih banyak berasal dari kelompok motivasi yang buruk (50\%). Sedangkan kualitas data baik lebih banyak berasal dari kelompok motivasi yang baik (66.7\%).

Motivasi adalah keadaan dalam diri pribadi seseorang yang mendorong keinginan individu untuk melakukan kegiatan-kegiatan tertentu, guna mencapai suatu tujuan. Motivasi kerja adalah sesuatu menimbulkan semangat atau dorongan kerja. Motivasi yang ada pada diri seseorang akan mewujudkan suatu perilaku yang diarahkan pada tujuan mencapai sasaran kerja.

Berdasarkan hasil wawancara, diketahui bahwa persepsi bidan desa mengenai pelaporan data PWS KIA yang lengkap, akurat dan tepat waktu sangat penting (100\%) dan formulir pelaporan PWS KIA tidak sulit dan rumit dalam pengisiannya $(80 \%)$. Bidan desa mengguna- kan formulir pelaporan data dari Puskesmas (100\%).

Berdasarkan tabulasi silang diketahui bahwa kualitas data tidak baik lebih banyak berasal dari kelompok persepsi pelaporan yang baik (50\%). Sedangkan kualitas data yang baik lebih banyak berasal dari kelompok persepsi pelaporan yang buruk (66.7\%). Hal ini menunjukan persepsi tidak semata mata berkontribusi terhadap kuaitas data PWS KIA. Petugas lebih banyak didorong oleh kewajiban pelaporan PWS KIA, daripada persepsi tentang pelaporan PWS KIA

Hasil ini juga sejalan dengan penelitian Hari Basuki di Jawa Timur bahwa pengetahuan dan sikap petugas kesehatan tidak berpengaruh terhadap kualitas data, dalam hal ini akurasi data (Hari, 2005 ). Namun demikian, dalam penggunaan Buku KIA oleh kader kesehatan, menurut penelitian yang dilakukan oleh Colti di Puskesmas Kalibagor, Kabupaten Purbalingga dinyatakan bahwa ada hubungan pengetahuan terhadap kualitas penggunaan Buku KIA. (Colti, 2014 ). Hal ini menunjukkan bahwa, peran pengetahuan antara petugas dan Ibu berbeda dalam kualitas penggunaan data KIA.

Berdasarkan hasil wawancara, diketahui bahwa kegiatan pelayanan KIA tidak menjadi beban bagi bidan desa dalam melakukan pencatatan data secara lengkap, akurat dan pengumpulan laporan dengan tepat waktu, karena kegiatan pelayanan KIA tersebut sudah menjadi tugas pokok dan fungsi sebagai bidan. Sebagian besar bidan desa merasa kegiatan pencatatan dan pelaporan tidak sederhana dan menyulitkan $(80 \%)$. Tugas tambahan di luar ruangan membuat bidan desa tidak melakukan pelaporan data PWS KIA dengan lengkap dan tepat waktu (100\%).

Berdasarkan tabulasi silang dapat diketahui bahwa kualitas data tidak baik lebih banyak berasal dari bidan desa yang memiliki beban kerja berat (50\%). Sedangkan kualitas data yang baik lebih banyak berasal dari bidan desa yang memiliki beban kerja ringan (66.7\%).

Beban kerja sangat mempengaruhi kinerja pada setiap karyawan. Semakin berat beban kerja pada karyawan, maka akan semakin mendorong kinerja karyawan tersebut. Beban kerja kuantitatif memberikan pengaruh paling besar terhadap kinerja perawat. 
Tabel 5. Tabulasi Silang Variabel Organisasi dan SDM dengan Kualitas Data

\begin{tabular}{|c|c|c|c|c|c|c|}
\hline & & \multicolumn{4}{|c|}{ Kualitas Data } & \multirow{3}{*}{ Total } \\
\hline \multirow{2}{*}{\multicolumn{2}{|c|}{ Variabel }} & \multicolumn{2}{|c|}{ Tidak Baik } & \multicolumn{2}{|c|}{ Baik } & \\
\hline & & $\mathrm{f}$ & $\%$ & $\mathrm{f}$ & $\%$ & \\
\hline \multirow{2}{*}{ Supervisi } & Buruk & 0 & 0 & 1 & 100 & 100 \\
\hline & Baik & 2 & 50 & 2 & 50 & 100 \\
\hline \multirow{2}{*}{ Ketersediaan Fasilitas } & Buruk & 0 & 0 & 0 & 0 & 0 \\
\hline & Baik & 2 & 40 & 3 & 60 & 100 \\
\hline \multirow{2}{*}{ Motivasi } & Buruk & 1 & 50 & 1 & 50 & 100 \\
\hline & Baik & 1 & 33.3 & 2 & 66.7 & 100 \\
\hline \multirow{2}{*}{ Persepsi Pelaporan } & Buruk & 1 & 33.3 & 2 & 66.7 & 100 \\
\hline & Baik & 1 & 50 & 1 & 50 & 100 \\
\hline \multirow{2}{*}{ Beban Kerja } & Ringan & 1 & 33.3 & 2 & 66.7 & 100 \\
\hline & Berat & 1 & 50 & 1 & 50 & 100 \\
\hline \multirow{2}{*}{ Masa Kerja } & Lama $(>6 \mathrm{Th})$ & 1 & 33.3 & 2 & 66.7 & 100 \\
\hline & $\operatorname{Baru}(<6 \mathrm{Th})$ & 1 & 50 & 1 & 50 & 100 \\
\hline
\end{tabular}

Sumber : data primer

Keterangan : Kategori variabel selain masa kerja dengan menggunakan nilai median skor variabel.

Untuk meringankan beban kerja dan meningkatkan kualitas informasi PWS KIA sebagai hasil kinerja Bidan Desa, maka diperlukan Teknologi Informasi. Teknologi Informasi telah terbukti meningkatkan kualitas layanan dan riwayat kesehatan penderita HIV/AIDS di klinik pelayanan Kesehatan (Patricia et al, 2012).

Berdasarkan hasil wawancara, diketahui bahwa masa kerja bidan desa minimum 4 tahun, maksimum 9 tahun dan rata-rata masa kerja bidan desa di Kecamatan Bidan desa selama 6 tahun.

Berdasarkan tabulasi silang dapat diketahui bahwa kualitas data yang tidak baik lebih banyak berasal dari kelompok bidan desa yang memiliki masa kerja baru ( $<6$ tahun) dengan persentase 50\%. Sedangkan kualitas data yang baik lebih banyak berasal dari kelompok bidan desa yang memiliki masa kerja lama ( $\geq 6$ tahun) dengan persentase (66.7\%).

Kualitas data dalam hal ini merupakan hasil kinerja dari pencatatan dan pelaporan bidan desa. Masa kerja juga memiliki keterkaitan dengan kualitas data. Semakin lama seorang individu bekerja maka akan menunjukkan hasil kinerja yang baik. Pengalaman merupakan salah satu composite variable dari variabel individu yang berpengaruh terhadap perilaku atau kinerja.

\section{Penutup}

Hasil penelitian menunjukkan bahwa kelengkapan dokumen pencatatan PWS KIA yang terbesar pada Kohort dan Buku KIA ( $100 \%)$. Rata rata kelengkapan data sebesar $50 \%$. Keakurasian data rata rata $70 \%$. Ketepatan waktu pelaporan rata rata sebesar $80 \%$. Skor Rata rata kualitas data sebesar $66,9 \%$. Hasil tabulasi silang menunjukkan bahwa prosentase besar kualitas data PWS yang baik, ditunjukkan dengan prosentase yang besar pada persepsi fasilitas dan motivasi yang baik, beban kerja yang ringan dan masa kerja yang lama. Puskesmas Duren diharapkan memberikan reward atas prestasi bidan di desa dalam pencatatan dan pelaporan data KIA, untuk terus memotivasi petugas, terutama petugas dengan masa kerja yang baru, untuk meningkatkan kualitas data pelaporan PWS KIA serta perlunya penggunaan Teknologi Informasi untuk mengurangi beban kerja Bidan supaya kualitas data semakin baik, dan fasilitas yang mendukung kualitas data PWS KIA. 


\section{Daftar Pustaka}

Dinkes Prop Jateng. 2013. Profil Kesehatan Jawa Tengah

Depkes RI. 2009, Pedoman PWS KIA. Depkes RI. Jakarta.

Edi M Haryanto, 2001. Beberapa Faktor yang Berhubungan dengan Kinerja Koordinator Imunisasi Puskesmas di Kota Semarang. Tesis. Semarang: Program Pasca Sarjana UNDIP.

Hari Basuki N. 2005, Pengaruh pengetahuan dan sikap Petugas terhadap kualitas data Kesehatan, Info Kesehatan Masyarakat, 9 ( 3 ) : 149 - 154

Ingan Tarigan, 2009. Kualitas data imunisasi Rutin berdasarkan metode Data Quality Self Assesment (DQS), Media Litbang Kesehatan, 19 (1) : 16-24

Kemenkes RI. 2012, Road Map Sistem Informasi Kesehatan Nasional Tahun 2011-2014. Jakarta: Kemenkes RI.

Patricia H Virza, Bongguk Jin, Jesse Thomas, Sergei Virodov. 2012. Electronic Health Information technology as a tool for improving quality of care and health outcomes for HIV / AIDS Patients. International Journal of Medical Informatics, $81: 39-45$

Ratih Wirapuspita, 2013. Insentif dan Kinerja Kader Posyandu.Jurnal Kemas, 9 (1) : 58-65 